\title{
Major depression in primary care: making the diagnosis
}

\author{
Chung Wai Mark $\underline{N g}^{1}$, MMed, FCFP, Choon How $\underline{H o w}^{2}$, MMed, FCFP, Yin Ping $\underline{N g}^{3,4}$, MB BCh BAO, DrPsych
}

Susan came to your clinic with her grandson Sam for an unscheduled consultation two months ahead of her next chronic diseases review. Susan kept looking down and heaving sighs now and then. Sam reported that his grandmother had not been herself since her close cousin passed away two months ago, and that she had since stopped knitting and following Korean drama serials. Her sleep and appetite had also been affected in the last month. His family had asked Sam to take his grandmother for an assessment.

\section{WHAT IS MAJOR DEPRESSION?}

Major depression is a mood disorder that presents with either a persistent feeling of sadness or loss of pleasure, or both. ${ }^{(1)}$

\section{HOW COMMON IS THIS IN MY PRACTICE?}

The Singapore Mental Health Study (SMHS) 2010 reported that major depression was the most common mental illness with a lifetime prevalence of $5.8 \%$, followed by alcohol abuse and obsessive compulsive disorder. ${ }^{(2)}$ However, only $18 \%$ of patients with mental disorders sought help from primary care practitioners. ${ }^{(2)}$ The risk of major depression is significantly higher in the older population. ${ }^{(3)}$ As such, primary care doctors need to be familiar with the diagnosis and management of major depression.

\section{WHAT CAN I DO IN MY PRACTICE?}

\section{Screening - particularly in patients at risk}

Major depression is a chronic illness of considerable morbidity, with high rates of relapse and recurrence; ${ }^{(4,5)}$ however, many patients suffering from major depression do not seek help early. ${ }^{(2,6)}$ This could be due to various factors: lack of insight into their medical condition; the stigma associated with the label of mental illness; and financial factors. ${ }^{(6)}$ The SMHS found that the median time between the onset of illness and help-seeking was five years. ${ }^{(2)}$ Hence, viewing screening as the first step, followed by diagnosis, early treatment and follow-up, was shown to result in better outcomes. ${ }^{(7,8)}$

There are many good recommendations that advocate screening for major depression. The clinical practice guidelines on major depression published by the Ministry of Health, Singapore, in 2012 recommend screening for major depression in high-risk persons where the benefits outweigh the risks. ${ }^{(9)}$ The United States Preventive Services Task Force recommends screening for major depression in the general adult population and having adequate systems in place to ensure proper diagnosis, treatment and follow-up. ${ }^{(10)}$ While the Canadian Task Force on Preventive Healthcare does not recommend routine screening of adults in primary care, it advocates vigilance for major depression in patients with risk factors and symptoms of insomnia, low mood, anhedonia and suicidal thoughts. ${ }^{(1)}$ The 2016 updated guidelines from the National Institute for Health and Care Excellence, United Kingdom, recommend that clinicians screen for major depression in persons who have chronic medical conditions with impaired function, as well as persons with a past history of major depression, by asking if low mood, hopelessness and anhedonia are also present. ${ }^{(12)}$

\section{Which patients are at greater risk of major depression?}

Anyone with a past depressive episode is at risk of further episodes, as the natural course of major depression involves frequent relapses. ${ }^{(5)}$ There is a bidirectional relationship between major depression and chronic disease. The SMHS showed that almost half of the persons with major depression had at least one chronic physical condition. ${ }^{(2)}$ Similarly, individuals with chronic physical conditions are known to be at greater risk of major depression. ${ }^{(13-15)}$ For example, the prevalence of major depression is higher in persons with chronic medical conditions such as heart disease, stroke and diabetes mellitus; ${ }^{(16,17)}$ coexisting major depression is associated with poorer prognosis and an increased rate of complications that are related to these conditions. ${ }^{(18)}$ A significant association was found between major depression and a number of diabetic complications. Those who were depressed were also more likely to die after a heart attack compared to non-depressed patients. ${ }^{(19)}$

Apart from the usual symptoms of major depression such as insomnia and low energy level, patients often present to primary care doctors with somatic symptoms. ${ }^{(20,21)}$ Physical symptoms associated with major depression include backaches, nonspecific musculoskeletal complaints, having multiple (three or more) somatic complaints, and having vague complaints. ${ }^{(22)}$ Patients may experience deteriorating memory as well. A review has shown that major depression is associated with attention deficit and poor cognitive functioning, particularly when the patient is acutely depressed. ${ }^{(23)}$ The elderly, in particular, are less likely to report low mood, instead presenting with physical complaints and deterioration in cognitive ability. ${ }^{(24)}$

${ }^{1}$ SingHealth Polyclinics, ${ }^{2}$ Care and Health Integration, Changi General Hospital, Singapore, ${ }^{3}$ Penang Medical College, ${ }^{4}$ Penang Adventist Hospital, Penang, Malaysia Correspondence: Dr Ng Chung Wai Mark, Senior Consultant and Family Physician, SingHealth Polyclinics - Outram, Health Promotion Board Building Level 2, 3 Second Hospital Avenue, Singapore 168937.ng.chung.wai@singhealth.com.sg 
Clinicians should also pay attention to life event stressors, as these are associated with the onset of major depression, particularly in persons with a genetic predisposition. ${ }^{(25,26)}$ Such stressors include recent loss or bereavement, physical or emotional abuse, incidents involving humiliation, and difficult relationships. ${ }^{(27)}$ Since major depression often coexists with other psychiatric disorders (e.g. anxiety disorders, substance abuse and somatoform disorders), ${ }^{(28,29)}$ patients who present with these diagnoses should be screened for major depression, and vice versa. Box 1 shows a summary of risk factors for major depression.

\section{How do I screen for major depression in primary care?}

The Patient Health Questionaire-2 (PHQ-2; Table I) is a two-item tool that can be used by primary care practitioners in the busy outpatient setting with a high patient load. ${ }^{(34)}$ Both items in PHQ-2 are listed as key criteria for the diagnosis of major depression in the fifth edition of the Diagnostic and Statistical Manual of Mental Disorders (DSM-5). ${ }^{(1)}$ The specificity for major depression in primary care was as high as $90 \%$, using a threshold score $\geq 3,{ }^{(34)}$ but sensitivity findings were variable, ranging from $74 \%$ to $83 \% .^{(34,35)}$ Due to its brevity, the recommendation is to use the PHQ-2 simply as a screening tool for major depression and not for assessing disease severity. Among primary care doctors, ${ }^{(35)}$ some recommend using a threshold score $\geq 2$ (instead of $\geq 3$ ) to improve sensitivity. Patients who obtain a score $\geq 2$ should proceed to the nine-item Patient Health Questionnaire-9 (PHQ-9).

The PHQ-9 ${ }^{(34)}$ (Table II) exclusively focuses on the nine diagnostic criteria for major depression listed in the DSM-5.(1) Major depression is diagnosed if a score $\geq 2$ is obtained for five or more of the nine symptom criteria, with low mood or anhedonia being one of the criteria. For the criterion on suicide ideation ('thoughts that you would be better off dead or of hurting yourself in some way'), a score $\geq 1$ is counted, i.e. regardless of duration. The advantages of PHQ-9 are its brevity, sensitivity and specificity, and its utility as both a diagnostic and severity measure for major depression.

The Beck Depression Inventory $(\mathrm{BDI})^{(36)}$ is a 21 -item questionnaire that was first developed in 1961. The items cover affective, cognitive and somatic aspects of major depression. There were concerns that the somatic aspects of the inventory could lead to spuriously high estimates of major depression in patients with chronic medical conditions. A shorter version, the BDI-Fast Screen or BDI-FS (previously called BDI-Primary Care), was developed by removing the somatic components of the BDI. Each of the seven items (sadness, pessimism, past failure, anhedonia, self-dislike, self-criticalness and suicidal ideation) is rated on a four-point scale ranging from 0 to $3 .^{(37)}$ A cutoff score $\geq 4$ was found to be sensitive and specific for identifying major depression among outpatients. ${ }^{(38,39)}$

The Geriatric Depression Scale (GDS) $)^{(40)}$ is a 30 -item depression questionnaire specifically designed for use in older adults. The GDS assesses the affective and cognitive aspects of major depression, but intentionally omits assessment for somatic symptoms. The rationale is that such an assessment may be nondiscriminatory in the elderly due to the physiological effects of

\section{Box 1. Persons at risk of major depression include those with:}

- Prior depressive episode ${ }^{(5)}$

- Recent stressful life event ${ }^{(25,26)}$

- Family history of major depression ${ }^{(5)}$

- Chronic medical conditions (28,30,31) $^{(2,0)}$

- Cognitive impairment or dementia ${ }^{(24,32)}$

- Anxiety and substance abuse ${ }^{(28,33)}$

- Multiple physical complaints, vague complaints or unexplained physical symptoms ${ }^{(21,31)}$

Table I. Patient Health Questionnaire-2. ${ }^{(34)}$

\begin{tabular}{ll}
\hline $\begin{array}{l}\text { Over the past two weeks, how often have you been bothered by } \\
\text { any of the following problems? }\end{array}$ \\
\hline Low mood & $0=$ Not at all \\
Feeling down, depressed & $1=$ Several days \\
and hopeless? & $2=$ More than half the days \\
& $3=$ Nearly every day \\
Anhedonia & $0=$ Not at all \\
Little interest or pleasure & $1=$ Several days \\
in doing things? & $2=$ More than half the days \\
& $3=$ Nearly every day \\
\hline
\end{tabular}

Total point score: If a score $\geq 2$ is obtained, proceed to the nine-item Patient Health Questionnaire-9. ${ }^{(35)}$

age and presence of chronic medical conditions. A score $\geq 11$ on the GDS has a $84 \%$ sensitivity and $95 \%$ specificity for major depression in elderly patients. ${ }^{(40)}$ The questionnaire is easy to use, as the items require a yes-no response. However, the sheer number of items may be cumbersome in the busy outpatient setting. Shorter versions of the GDS, including 15-item, ten-item, four-item and one-item versions, have been found to be helpful in identifying depressive symptoms in elderly outpatients. ${ }^{(41)}$

\section{Criteria and differentials for major depression}

The primary care practitioner should be familiar with the criteria for the diagnosis of major depression, while being mindful of conditions that can mimic or coexist with major depression. An essential first step to management is making an accurate diagnosis. ${ }^{(42)}$ A meta-analysis has shown that, while primary care doctors are able to rule out major depression in persons who are not depressed, false positives are common in persons who are labelled as depressed. ${ }^{(43)}$ There is also reluctance to label patients as depressed even though they fulfil the diagnostic criteria. Underdiagnosing major depression leads to delay or non-treatment, while overdiagnosing it leads to antidepressant overuse, inappropriate referrals to psychiatric services and missing organic diseases that are mistaken as major depression. ${ }^{(44,45)}$

\section{Major depression}

The DSM-5 provides a set of criteria that should be fulfilled in order to diagnose major depression (Box 2). ${ }^{(1)}$ The patient is said to have major depression if low mood or anhedonia (defined as loss of interest or pleasure) is present nearly every day for two or more weeks, together with other symptoms. However, it is important to note that the DSM-5, like any other diagnostic tool, serves as a guideline and should not replace clinical judgement. 
Table II. Patient Health Questionnaire-9.(34)

\begin{tabular}{|c|c|c|c|c|c|}
\hline \multicolumn{6}{|c|}{ Over the last two weeks, how often have you been bothered by any of the following problems? } \\
\hline \multicolumn{2}{|r|}{ Criterion } & \multirow{2}{*}{$\frac{\text { Not at all }}{0}$} & \multirow{2}{*}{$\frac{\text { Several days }}{1}$} & \multirow{2}{*}{$\begin{array}{c}\text { More than half the days } \\
2\end{array}$} & \multirow{2}{*}{$\frac{\text { Nearly every day }}{3}$} \\
\hline 1. & Little interest or pleasure in doing things & & & & \\
\hline 2. & Feeling down, depressed or hopeless & 0 & 1 & 2 & 3 \\
\hline 3. & Trouble falling or staying asleep, or sleeping too much & 0 & 1 & 2 & 3 \\
\hline 4. & Feeling tired or having little energy & 0 & 1 & 2 & 3 \\
\hline 5. & Poor appetite or overeating & 0 & 1 & 2 & 3 \\
\hline 6. & $\begin{array}{l}\text { Feeling bad about yourself - or that you are a failure } \\
\text { or have let yourself or your family down }\end{array}$ & 0 & 1 & 2 & 3 \\
\hline 7. & $\begin{array}{l}\text { Trouble concentrating on things, such as reading the } \\
\text { newspaper or watching television }\end{array}$ & 0 & 1 & 2 & 3 \\
\hline 8. & $\begin{array}{l}\text { Moving or speaking so slowly that other people could } \\
\text { have noticed? Or the opposite - being so fidgety or } \\
\text { restless that you have been moving around a lot more } \\
\text { than usual }\end{array}$ & 0 & 1 & 2 & 3 \\
\hline 9. & $\begin{array}{l}\text { Thoughts that you would be better off dead or of } \\
\text { hurting yourself in some way }\end{array}$ & 0 & 1 & 2 & 3 \\
\hline
\end{tabular}

Total point score: Major depression is diagnosed if a score $\geq 2$ is obtained for five or more of the nine symptom criteria, with Criterion 1 (low mood) or 2 (anhedonia) being one of the criteria. For Criterion 9 , a score $\geq 1$ is counted, i.e. regardless of duration.

\section{Box 2. DSM-5 criteria for major depressive episode ${ }^{(1)}$}

- At least five of the following symptoms are present nearly every day during the same two-week period, as reported by the patient or observed by others:

1. Low mood

2. Anhedonia (markedly diminished interest or pleasure in all, or almost all, activities)

3. Insomnia or hypersomnia

4. Fatigue or loss of energy

5. Significant (e.g. $5 \%$ of body weight within a month) unexplained weight loss or gain, or change in appetite

6. Psychomotor agitation or retardation

7. Indecisiveness or poor concentration

8. Feelings of worthlessness or inappropriate guilt

9. Recurrent thoughts of death, recurrent suicidal ideation without a specific plan, a suicide attempt or a specific plan for suicide

- At least one of the symptoms is low mood or anhedonia.

- Symptoms represent a change from previous functioning and cause clinically significant distress or impairment in social, occupational or other important areas of functioning.

- Symptoms are not clearly attributable to another medical condition (including psychiatric conditions) or physiological effects of substance.

- There has never been a manic or hypomanic episode.

For example, a patient who presents with persistent low mood and anhedonia associated with hopelessness and suicidal ideation for ten days (hence not fulfilling the criteria of at least two weeks) should be managed in the same way as a patient with major depression. In the DSM-5 (which replaces the DSM-IV) criteria, recent bereavement is now recognised as one of the stressors that can precipitate major depression; it is thus not an exclusion criterion for the diagnosis of major depression.

The physician should also ensure that the symptoms of major depression are not attributable to another organic or psychiatric medical condition. Therefore, evaluation should take into consideration a number of organic illnesses that can mimic or coexist with major depression. ${ }^{(46)}$ The following conditions should be considered, as they determine both management and prognosis.

\section{Persistent depressive disorder}

Persistent depressive disorder (PDD) is characterised by milder depressive symptoms that persist for at least two years, or at least one year in children or adolescents. ${ }^{(1)}$ Patients should not be asymptomatic for more than two months. PDD can be underreported, as its symptoms are chronic and less severe, and form part of the patient's regular day-to-day experience. ${ }^{(1)}$ Its symptoms are less likely to resolve compared to major depression, ${ }^{(1)}$ and may require a longer treatment period, more psychotherapy sessions, and/or higher doses of antidepressant medication. Psychotherapy may also be less effective for the treatment of PDD symptoms. ${ }^{(47)}$

\section{Adjustment disorder with depressed mood}

An adjustment disorder is an emotional response to a stressful event such as marital or relationship problems, loss of employment or acute illness. ${ }^{(48)}$ Patients can present with low mood, but this diagnosis is made only if the full criteria for a major depressive episode are not met. ${ }^{(1)}$ It can cause significant morbidity and increase suicide risk.

\section{Bipolar disorder}

Patients with bipolar disorder are often misdiagnosed as having unipolar major depression, particularly at initial presentation and in the primary care setting. A large proportion may remain misdiagnosed for up to ten years. ${ }^{(49,50)}$ There are various reasons for this. Patients with bipolar disorder are much more likely to present with low mood rather than mania or hypomania, ${ }^{(51,52)}$ and thus are labelled as having major depression. Hypomania 
in bipolar II disorder is often associated with increased creativity and energy with no impairment in function, ${ }^{(53)}$ which patients may not see as negative and often do not seek medical attention for. Misdiagnosis of bipolar disorder as major depression leads to inappropriate treatment with antidepressants instead of a mood stabiliser. As this contributes to worsening outcomes and may induce mania or rapid cycling, ${ }^{(54-56)}$ any patient who presents with symptoms of major depression should be evaluated for possible bipolar disorder.

A history of mania or hypomania is the main feature that distinguishes bipolar disorder from major depression. Manic episodes are present in bipolar I disorder, whereas the patient with bipolar II disorder experiences only hypomania and major depression without any manic episodes. ${ }^{(1)}$ Both mania and hypomania are characterised by an abnormally elevated or irritable mood, with persistent increased energy and a noticeable change from baseline behaviour. Behavioural changes may include a decreased need for sleep, an inflated self-esteem or grandiosity, increased goal-directed activity, being more talkative, and an excessive involvement in activities that are likely to have ill consequences, such as uncontrolled spending sprees, bad investments and sexual promiscuity. ${ }^{(1)}$ In mania, unlike hypomania, the patient's symptoms are of at least a week's duration and result in impaired functioning or require hospitalisation. Psychosis may or may not be present. It is important to check that the symptoms during these episodes are different, more prominent and more persistent as compared to the baseline. ${ }^{(1)}$ When taking a history, useful questions include: Have you ever experienced a period of time when you felt happier or more energetic than usual, for no particular reason? And if so, did you notice during such times that your thoughts were more rapid, or you had more ideas, required less sleep or were more talkative than usual? Did others notice this too? What did they say? How long did these last? Did they have any impact or effect on your life, work or relationships?

Other features that may help distinguish bipolar disorder from major depression include younger age of onset, a family history of bipolar disorder, a higher number of previous depressive episodes (e.g. too numerous to recall), atypical depressive features (e.g. hypersomnia instead of insomnia or hyperphagia instead of poor appetite), fewer somatic symptoms and increased phobias (e.g. of the dark, strangers or crowds). ${ }^{(57-59)}$ In patients who are misdiagnosed with major depression and started on antidepressants, rapid 'switching' from low mood to a manic or hypomanic state may occur. ${ }^{(54,55,58)}$ Hence, responding to antidepressant therapy too rapidly should raise the suspicion of a misdiagnosis as well.

\section{Neurological conditions}

Neurological conditions such as dementia, Parkinson's disease and multiple sclerosis have symptoms that overlap with those of major depression. ${ }^{(60)}$ In Parkinson's disease, low mood and other affective symptoms may even precede motor symptoms. Persons with cognitive impairment may present with low mood; conversely, those who have major depression may have poor concentration with impaired executive functioning and perform poorly at cognitive tests. ${ }^{(23,61)}$ Major depression itself may be a risk factor for developing dementia. ${ }^{(61,62)}$ Assessment should be guided by clinical suspicion. Neurological examination and cognitive assessment using well-known tools such as the Mini-Mental State Examination and Abbreviated Mental Test are important aspects of evaluation, particularly for older patients presenting with low mood.

\section{Other organic conditions}

In a person who presents predominantly with somatic symptoms, the primary care physician needs to first exclude any organic disease. ${ }^{(21,31)}$ Depending on the symptomatology, the scope of organic conditions to consider can be wide, especially with elderly patients. Organic conditions can also coexist or masquerade as major depression (e.g. occult malignancy or even infections). ${ }^{(63,64)}$ Patients should have their thyroid function tested, as thyroid dysfunction may present with low mood and other nonspecific somatic symptoms. However, minor abnormalities in thyroid function should be interpreted with caution; major depression may be associated with subtle changes in thyroid function. ${ }^{(65,60)} \mathrm{A}$ useful method of differentiating major depression in medical patients, who may present with somatic symptoms similar to those found in major depression, is to ask about cognitive symptoms such as negative thinking, inappropriate guilt and low self-esteem. ${ }^{(67)}$

\section{Drugs and substance abuse}

Major depression is a risk factor for and is often associated with substance abuse, including that of alcohol, ${ }^{(33)}$ which may be under-recognised in elderly patients. ${ }^{(68,69)}$ In terms of lifetime prevalence, it has been shown that alcohol abuse is the second most common mental disorder among adults in Singapore. ${ }^{(2)}$ Tactful enquiry using an open-ended question about alcohol intake has been shown to enhance the sensitivity of the CAGE questionnaire. ${ }^{(70,71)}$ The patient's medication history is important, as even prescription drugs have been cited as potential causes of major depression. ${ }^{(72)} \mathrm{A}$ review found strong association between major depression and finasteride, isotretinoin and a smoking cessation drug, varenicline. ${ }^{(73)}$ The authors recommended that physicians exercise caution when prescribing these medications and strongly weigh risk-benefit considerations, particularly in persons who are predisposed to major depression. ${ }^{(73)}$ Fortunately, evidence implicating medications commonly prescribed in primary care was shown to be inconclusive. These medications include beta-blockers, calcium channel blockers, angiotensinconverting enzyme inhibitors and angiotensin II receptor blockers. ${ }^{(73)}$

\section{Assessing the severity of major depression}

The DSM-5 ${ }^{(1)}$ defines the severity of major depression based on the number of criterion symptoms, severity of those symptoms and degree of functional disability. Major depression is classified as mild if (a) the patient has very few, if any, symptoms in excess of the five required to fulfil the criteria for diagnosis; (b) the symptoms are manageable; and (c) functional impairment is minor (e.g. the patient is still able to work). At the opposite end of the spectrum, 
severe major depression has (a) a substantially greater number of symptoms than that required to make the diagnosis; (b) seriously distressing and unmanageable symptoms; and (c) extensive impairment of social and occupational functioning. For moderate major depression, the number of symptoms, the intensity of symptoms and/or functional impairment are in-between those specified for 'mild' and 'severe'.

The severity of major depression has an important bearing on the urgency and mode of treatment, setting in which the patient is to be managed and frequency of follow-up visits. For example, psychotherapy may be used as the first-line treatment for mild to moderate major depression, whereas pharmacotherapy is recommended for moderate to severe major depression. ${ }^{(74)}$ In patients with previous episodes of moderate to severe depression, who present with mild symptoms, the first-line treatment should be drug therapy. ${ }^{(12)}$ Those who have psychotic features should be managed by psychiatric services in tertiary care, while patients who are acutely suicidal should be hospitalised for urgent psychiatric evaluation.

\section{CONCLUSION}

Major depression is the most prevalent mental disorder in Singapore. Patients often present with somatic nonspecific complaints apart from the usual symptoms. Major depression is also common among patients with chronic conditions; there is a bidirectional relationship between the two factors. As the first point of contact for patients, the primary care practitioner is in a unique position to diagnose and manage major depression. Another important aspect of evaluating a person with major depression is performing a suicide risk assessment, which is described in our next article in this three-part series.

You identified the death of Susan's cousin as a life event that had a significant emotional impact on her. Using the PHQ-2 and PHQ-9, you diagnosed Susan with major depression. You started her on a serotoninspecific reuptake inhibitor and referred her to a clinical psychologist for cognitive behaviour therapy.

\section{TAKE HOME MESSAGES}

1. Major depression is the most common mental disorder in the community and patients often present with somatic symptoms.

2. Major depression is potentially a chronic illness that has considerable morbidity, and high relapse and recurrence rates.

3. There is a bidirectional relationship between major depression and chronic diseases.

4. Clinical tools available for screening for major depression include the common PHQ-2, PHQ-9 and BDI.

5. The severity of major depression, according to the DSM-5, increases with the number of criterion symptoms present and degree of functional disability.
ABSTRACT Major depression is a common condition seen in the primary care setting, often presenting with somatic symptoms. It is potentially a chronic illness with considerable morbidity, and a high rate of relapse and recurrence. Major depression has a bidirectional relationship with chronic diseases, and a strong association with increased age and coexisting mental illnesses (e.g. anxiety disorders). Screening can be performed using clinical tools for major depression, such as the Patient Health Questionaire-2, Patient Health Questionaire-9 and Beck Depression Inventory, so that timely treatment can be initiated. An accurate diagnosis of major depression and its severity is essential for prompt treatment to reduce morbidity and mortality. This is the first of a series of articles that illustrates the approach to the management of major depression in primary care. Our next articles will cover suicide risk assessment in a depressed patient and outline the basic principles of management and treatment modalities.

Keywords: major depression, primary care

\section{REFERENCES}

1. American Psychiatric Association. Diagnostic and Statistical Manual of Mental Disorders. 5th ed. Washington, DC: American Psychiatric Association, 2013.

2. Chong SA, Abdin E, Vaingankar JA, et al. A population-based survey of mental disorders in Singapore. Ann Acad Med Singapore 2012; 41:49-66.

3. Subramaniam M, Abdin E, Sambasivam R, et al. Prevalence of depression among older adults--results from the Well-being of the Singapore Elderly study. Ann Acad Med Singapore 2016; 45:123-33.

4. Judd LL, Akiskal HS, Maser JD, et al. A prospective 12-year study of subsyndromal and syndromal depressive symptoms in unipolar major depressive disorders. Arch Gen Psychiatry 1998; 55:694-700.

5. Burcusa SL, lacono WG. Risk for recurrence in depression. Clin Psychol Rev 2007; 27:959-85.

6. Kessler RC, Berglund PA, Bruce ML, et al. The prevalence and correlates of untreated serious mental illness. Health Serv Res 2001; 36(6 Pt 1):987-1007.

7. Halfin A. Depression: the benefits of early and appropriate treatment. Am J Manag Care 2007; 13(4 Suppl):S92-7.

8. Kupfer DJ, Frank E, Perel JM. The advantage of early treatment intervention in recurrent depression. Arch Gen Psychiatry 1989; 46:771-5.

9. Ministry of Health, Singapore. Depression: $\mathrm{MOH}$ Clinical Practice Guidelines 1/2012 [online]. Available at: https://www.moh.gov.sg/content/ dam/moh_web/HPP/Doctors/cpg_medical/current/2012/depression/ Depression\%20CPG_R14_FINAL.pdf. Accessed October 21, 2016.

10. Siu AL; US Preventive Services Task Force (USPSTF), et al. Screening for depression in adults: US Preventive Services Task Force recommendation statement. JAMA 2016; 315:380-7.

11. Canadian Task Force on Preventive Health Care, Joffres M, Jaramillo A, et al. Recommendations on screening for depression in adults. CMAJ 2013; 185:775-82.

12. National Institute for Health and Care Excellence. Surveillance review of CG90: Depression in adults: management and treatment (update) [online]. Available at: https://www.nice.org.uk/guidance/cg90/documents/cg90-depression-inadults-update-surveillance-review-decision2. Accessed October 21, 2016.

13. Clarke DM, Currie KC. Depression, anxiety and their relationship with chronic diseases: a review of the epidemiology, risk and treatment evidence. Med J Aust 2009; 190(7 Suppl):S54-60.

14. Moussavi S, Chatterji S, Verdes E, et al. Depression, chronic diseases, and decrements in health: results from the World Health Surveys. Lancet 2007; 370:851-8.

15. Katon W, Ciechanowski P. Impact of major depression on chronic medical illness. J Psychosom Res 2002; 53:859-63.

16. Katon WJ. Epidemiology and treatment of depression in patients with chronic medical illness. Dialogues Clin Neurosci 2011; 13:7-23.

17. Hare DL, Toukhsati SR, Johansson P, Jaarsma T. Depression and cardiovascular disease: a clinical review. Eur Heart J 2014; 35:1365-72.

18. Simon GE. Treating depression in patients with chronic disease: recognition 
and treatment are crucial; depression worsens the course of a chronic illness. West J Med 2001; 175:292-3.

19. Lin EH, Rutter CM, Katon W, et al. Depression and advanced complications of diabetes: a prospective cohort study. Diabetes Care 2010; 33:264-9.

20. Kroenke K. The interface between physical and psychological symptoms Prim Care Companion CNS Disord 2003; 5(Suppl 7):11-8.

21. Kapfhammer HP. Somatic symptoms in depression. Dialogues Clin Neurosci 2006; 8:227-39.

22. Gerber PD, Barrett JE, Barrett JA, et al. The relationship of presenting physical complaints to depressive symptoms in primary care patients. J Gen Intern Med 1992; 7:170-3.

23. Hammar A, Ardal G. Cognitive functioning in major depression-a summary. Front Hum Neurosci 2009; 3:26. Available at: http://www.ncbi.nlm.nih. gov/pmc/articles/PMC2759342/. Accessed July 21, 2016.

24. Fiske A, Wetherell JL, Gatz M. Depression in older adults. Annu Rev Clin Psychol 2009; 5:363-89.

25. Kendler KS, Thornton LM, Gardner CO. Genetic risk, number of previous depressive episodes, and stressful life events in predicting onset of major depression. Am J Psychiatry 2001; 158:582-6.

26. Tennant C. Life events, stress and depression: a review of recent findings. Aust N Z J Psychiatry 2002; 36:173-82

27. Trangle M, Gursky J, Haight R, et al. Depression, adults in primary care [online]. Institute for Clinical Systems Improvement. Available at: https://www icsi.org/guidelines_more/catalog_guidelines_and_more/catalog_guidelines/ catalog behavioral health guidelines/depression/. Accessed August 5, 2016.

28. Hirschfeld RM. The comorbidity of major depression and anxiety disorders: recognition and management in primary care. Prim Care Companion J Clin Psychiatry 2001; 3:244-54.

29. Tylee A, Gandhi P. The importance of somatic symptoms in depression in primary care. Prim Care Companion J Clin Psychiatry 2005; 7:167-76.

30. Anderson RJ, Freedland KE, Clouse RE, Lustman PJ. The prevalence of comorbid depression in adults with diabetes: a meta-analysis. Diabetes Care $2001 ; 24: 1069-78$.

31. Goodwin GM. Depression and associated physical diseases and symptoms. Dialogues Clin Neurosci 2006; 8:259-65.

32. Alexopoulos GS. Depression in the elderly. Lancet 2005; 365:1961-70.

33. Davis L, Uezato A, Newell JM, Frazier E. Major depression and comorbid substance use disorders. Curr Opin Psychiatry 2008; 21:14-8.

34. Kroenke K, Spitzer RL, Williams JB. The PHQ-9: validity of a brief depression severity measure. J Gen Intern Med 2001; 16:606-13.

35. Arroll B, Goodyear-Smith F, Crengle S, et al. Validation of PHQ-2 and PHQ-9 to screen for major depression in the primary care population. Ann Fam Med 2010; 8:348-53.

36. Beck AT, Ward $\mathrm{CH}$, Mendelson M, Mock J, Erbaugh J. An inventory for measuring depression. Arch Gen Psychiatry 1961; 4:561-71.

37. Wang YP, Gorenstein C. Assessment of depression in medical patients: a systematic review of the utility of the Beck Depression Inventory-II. Clinics (Sao Paulo) 2013; 68:1274-87.

38. Steer RA, Cavalieri TA, Leonard DM, Beck AT. Use of the Beck Depression Inventory for Primary Care to screen for major depression disorders. Gen Hosp Psychiatry 1999; 21:106-11.

39. Winter LB, Steer RA, Jones-Hicks L, Beck AT. Screening for major depression disorders in adolescent medical outpatients with the Beck Depression Inventory for Primary Care. J Adolesc Health 1999; 24:389-94.

40. Yesavage JA, Brink TL, Rose TL, et al. Development and validation of a geriatric depression screening scale: a preliminary report. J Psychiatr Res 1982-1983; 17:37-49.

41. D'Ath P, Katona P, Mullan E, Evans S, Katona C. Screening, detection and management of depression in elderly primary care attenders. I: The acceptability and performance of the 15 item Geriatric Depression Scale (GDS15) and the development of short versions. Fam Pract 1994; 11:260-6.

42. National Collaborating Centre for Mental Health (UK). Depression: The Treatment and Management of Depression in Adults (Updated Edition) [online]. Leicester (UK): British Psychological Society, 2010. Available at: http://www.ncbi.nlm.nih.gov/books/NBK63748/. Accessed July 31, 2016.

43. Mitchell AJ, Vaze A, Rao S. Clinical diagnosis of depression in primary care: a meta-analysis. Lancet 2009; 374:609-19.

44. Boland RJ, Diaz S, Lamdan RM, Ramchandani D, McCartney JR. Overdiagnosis of depression in the general hospital. Gen Hosp Psychiatry 1996; 18:28-35.

45. Berardi D, Menchetti M, Cevenini N, et al. Increased recognition of depression in primary care. Comparison between primary-care physician and ICD-10 diagnosis of depression. Psychother Psychosom 2005; 74:225-30.

46. Bostwick JM, Rackley S. Recognizing mimics of depression: The '8 Ds'. Curr Psychiatry [online] 2012. Available at: http://hsrc.himmelfarb.gwu. edu/smhs psych facpubs/59. Accessed October 21, 2016.

47. Cuijpers P, Sijbrandij M, Koole SL, et al. The efficacy of psychotherapy and pharmacotherapy in treating depressive and anxiety disorders: a meta- analysis of direct comparisons. World Psychiatry 2013; 12:137-48.

48. World Health Organization. The ICD-10 Classification of Mental and Behavioural Disorders: Clinical Descriptions and Diagnostic Guidelines. Geneva: World Health Organization, 1992.

49. Lish JD, Dime-Meenan S, Whybrow PC, Price RA, Hirschfeld RM. The National Depressive and Manic-depressive Association (DMDA) survey of bipolar members. J Affect Disord 1994; 31:281-94.

50. Hirschfeld RM, Lewis L, Vornik LA. Perceptions and impact of bipolar disorder: how far have we really come? Results of the national depressive and manic-depressive association 2000 survey of individuals with bipolar disorder. J Clin Psychiatry 2003; 64:161-74.

51. Judd LL, Akiskal HS, Schettler PJ, et al. The long-term natural history of the weekly symptomatic status of bipolar I disorder. Arch Gen Psychiatry 2002; 59:530-7.

52. Judd LL, Akiskal HS, Schettler PJ, et al. A prospective investigation of the natural history of the long-term weekly symptomatic status of bipolar II disorder. Arch Gen Psychiatry 2003; 60:261-9.

53. Andreasen NC. The relationship between creativity and mood disorders. Dialogues Clin Neurosci 2008; 10:251-5.

54. Mclnerney SJ, Kennedy SH. Review of evidence for use of antidepressants in bipolar depression. Prim Care Companion CNS Disord [online] 2014; 16. Available at: http://www.ncbi.nlm.nih.gov/pmc/articles/ PMC4321017/. Accessed July 17, 2016.

55. Viktorin A, Lichtenstein $P$, Thase ME, et al. The risk of switch to mania in patients with bipolar disorder during treatment with an antidepressant alone and in combination with a mood stabilizer. Am J Psychiatry 2014; 171:1067-73.

56. Ghaemi SN, Boiman EE, Goodwin FK. Diagnosing bipolar disorder and the effect of antidepressants: a naturalistic study. J Clin Psychiatry 2000; 61:804-8; quiz 809.

57. Perlis RH, Brown E, Baker RW, Nierenberg AA. Clinical features of bipolar depression versus major depressive disorder in large multicenter trials. Am J Psychiatry 2006; 163:225-31

58. Culpepper L. The diagnosis and treatment of bipolar disorder: decisionmaking in primary care. Prim Care Companion CNS Disord [online] 2014; 16. Available at: http://www.ncbi.nlm.nih.gov/pmc/articles/ PMC4195640/. Accessed July 30, 2016.

59. Agosti V, Stewart JW. Atypical and non-atypical subtypes of depression: comparison of social functioning, symptoms, course of illness, co-morbidity and demographic features. J Affect Disord 2001; 65:75-9.

60. Rickards H. Depression in neurological disorders: Parkinson's disease, multiple sclerosis, and stroke. J Neurol Neurosurg Psychiatry 2005; 76(Suppl 1):i48-52.

61. Ganguli M. Depression, cognitive impairment and dementia: Why should clinicians care about the web of causation? Indian J Psychiatry 2009; 51(Suppl1):S29-34.

62. Mirza SS, Wolters FJ, Swanson SA, et al. 10-year trajectories of depressive symptoms and risk of dementia: a population-based study. Lancet Psychiatry $2016 ; 3: 628-35$

63. Ferrando SJ, Freyberg Z. Neuropsychiatric aspects of infectious diseases. Crit Care Clin 2008; 24:889-919, x.

64. Oerlemans ME, van den Akker M, Schuurman AG, Kellen E, Buntinx F. A meta-analysis on depression and subsequent cancer risk. Clin Pract Epidemiol Ment Health 2007 Dec 3; 3:29.

65. Dayan CM, Panicker V. Hypothyroidism and depression. Eur Thyroid J 2013; 2:168-79.

66. Hage MP, Azar ST. The link between thyroid function and depression. J Thyroid Res [online] 2012; 2012:590648. Available from: http://www. ncbi.nlm.nih.gov/pmc/articles/PMC3246784/. Accessed July 30, 2016.

67. Identifying and managing depression in the medical patient. Prim Care Companion J Clin Psychiatry 2005; 7:282-95.

68. Taylor $\mathrm{MH}$, Grossberg GT. The growing problem of illicit substance abuse in the elderly: a review. Prim Care Companion CNS Disord [online] 2012; 14: PCC.11 r01320. Available at: http://www.ncbi.nlm.nih.gov/pmc/articles/ PMC3505129/. Accessed July 30, 2016.

69. Culberson JW. Alcohol use in the elderly: beyond the CAGE. Part 1 of 2 : prevalence and patterns of problem drinking. Geriatrics 2006; 61:23-7.

70. Mayfield D, McLeod G, Hall P. The CAGE questionnaire: validation of a new alcoholism screening instrument. Am J Psychiatry 1974; 131:1121-3.

71. Steinweg DL, Worth H. Alcoholism: the keys to the CAGE. Am J Med 1993; 94:520-3.

72. Freis ED. Mental depression in hypertensive patients treated for long periods with large doses of reserpine. N Engl J Med 1954; 251:1006-8.

73. Rogers D, Pies R. General medical drugs associated with depression. Psychiatry (Edgmont) 2008; 5:28-41.

74. Nutt DJ, Davidson JR, Gelenberg AJ, et al. International consensus statement on major depressive disorder. J Clin Psychiatry [online] 2010; 71(suppl E1). Available at: http://article.psychiatrist. com/?ContentType=START\&ID=10006804. Accessed July 31, 2016. 


\section{SINGAPORE MEDICAL COUNCIL CATEGORY 3B CME PROGRAMME} (Code SMJ 201611A)

1. Major depression is a mood disorder that presents with either a persistent feeling of sadness or loss of pleasure, or both.

2. Major depression was found to be the most common mental illness in the Singapore Mental Health Study conducted in 2010.

3. Major depression is an episodic illness of considerable morbidity with a low rate of recurrence.

4. Many patients who suffer from major depression seek help within the first two weeks upon experiencing the early symptoms.

5. Timely screening coupled with diagnosis, early treatment and follow-up does not show better outcomes.

6. There is a bidirectional relationship between major depression and chronic disease.

7. Depressed patients in Singapore usually present to primary care clinics with insomnia and/or low energy level, rather than somatic symptoms.

8. Major depression is not commonly associated with attention deficit and poor cognitive functioning.

9. Clinicians should pay attention to life event stressors (e.g. recent loss or bereavement, abuse and incidents involving humiliation) as potential triggers for major depression.

10. The Patient Health Questionaire-2 (PHQ-2) is a two-item tool that can be adopted by most primary care practitioners, even in the busy outpatient setting.

11. The items in the PHQ-2 are derived from the two major criteria in the fifth edition of the Diagnostic and Statistical Manual of Mental Disorders (DSM-5) for the diagnosis of major depression.

12. The PHQ-2 can be used as a screening tool for major depression and to grade its severity when it is present.

13. Patients who obtain a score $\geq 2$ on the PHQ-2 should proceed to the nine-item Patient Health Questionnaire-9 (PHQ-9).

14. The PHQ-9 cannot be used as both a diagnostic and severity measure for major depression.

15. The Beck Depression Inventory-Fast Screen (BDI-FS; previously called BDI-Primary Care) was developed by removing the somatic components of the BDI.

16. The Geriatric Depression Scale assesses the affective and cognitive aspects of major depression as well as its somatic symptoms.

17. The DSM-5 provides a set of criteria that should be fulfilled in order to diagnose major depression.

18. Patients with bipolar disorder who present with a low mood are commonly diagnosed correctly.

19. Neurological conditions such as dementia, Parkinson's disease and multiple sclerosis do not have symptoms that overlap with those of major depression.

20. The DSM-5 defines the severity of depression based on the number of criterion symptoms, severity of those symptoms and degree of functional disability.

$\square$

\section{Doctor's particulars:}

Name in full

MCR number

Email address

\section{SUBMISSION INSTRUCTIONS:}

(1) Visit the SMJ website: http://www.smj.org.sg/current-issue and select the appropriate set of questions. (2) Provide your name, email address and MCR number. (3) Select your answers and click "Submit".

\section{RESULTS:}

(1) Answers will be published online in the SMJ January 2017 issue. (2) The MCR numbers of successful candidates will be posted online at the SMJ website by 30 December 2016. (3) Passing mark is $60 \%$. No mark will be deducted for incorrect answers. (4) The SMJ editorial office will submit the list of successful candidates to the Singapore Medical Council. (5) One CME point is awarded for successful candidates.

Deadline for submission: (November 2016 SMJ 3B CME programme): 12 noon, 23 December 2016. 